\title{
Assessment of Dynamic Routing Protocols for Increased Number of Workstations
}

\author{
Navita Komal \\ Department of Electronics \\ Technology,Guru Nanak Dev \\ University, Amritsar
}

\author{
RajanVohra \\ Asstt. Professor \\ Department of Electronics \\ Technology, Guru Nanak Dev \\ University, Amritsar
}

\author{
Ravinder Singh Sawhney \\ Sr. Lecturer \\ Department of Electronics \\ Technology, Guru Nanak Dev \\ University, Amritsar
}

\begin{abstract}
Paper describe the analysis of dynamic routing protocols EIGRP, OSPF and their combination i.e. OSPF-EIGRP for the scenario which have increasing number of workstations from 3 to 50 in steps working on three dissimilar applications (Database, E-mail, and HTTP). Initially three individual workstations were considered which then replaced by LANs of 10,25 and 50 in order to appraise the recompense of one scenario over the other. Simulation is carried out with the help of Optimized Network Engineering Tool (OPNET) which gives the better edge over the other network simulation tools available. The assessment is based on the two parameters namely E-mail Upload Response Time and HTTP Page Response Time. The results concluded that overall best performance can be achieved with the help of EIGRP protocol for the given scenario.
\end{abstract}

\section{Keywords}

EIGRP, OSPF, OSPF-EIGRP, OPNET, LAN, E-mail Upload Response Time, HTTP Page Response Time.

\section{INTRODUCTION}

In modern era, computer communication networks are growing rapidly day by day. Internet is a global system of interconnected computer networks and hence can be acknowledged as the largest computer network ever. Internet today plays a crucial role in the field of computer networks. Computer communication networks are based on a technology that provides the technical Infrastructure, where routing protocols are used to transmit packets across the Internet. Routing protocols specify how routers communicate with each other by disseminating information. The router has prior knowledge about the adjacent networks, which can assist in selecting the routes between two nodes. For interconnecting various computer networks Internet Protocol (IP) is the most widely used network layer protocol. Routing within an Autonomous System (AS) is known as Intra domain routing and the associated protocols are called intra domain routing protocols. Nowadays, the most widely used intra domain routing protocols are Open Shortest Path First (OSPF) and Enhanced Interior Gateway Routing Protocol (EIGRP). EIGRP is a Cisco proprietary distance-vector protocol based on Diffusing Update Algorithm (DUAL) [1] and OSPF on the other hand, is a link-state interior gateway protocol based on Dijkstra algorithm (Shortest Path First Algorithm) [2]. EIGRP and OSPF are dynamic routing protocols used in practical networks to disseminate network topology to the adjacent routers.

\section{LITERATURE REVIEW}

Many researchers in the past have compared the performance of the two dynamic routing protocols i.e. EIGRP and OSPF, based on different parameters. Ittiphon krinpayorm et al [3] showed the link recovery comparison between OSPF \& EIGRP and found that EIGRP is better than OSPF in both retransmission time and rerouting time after a link fails. Shafiul Hasan et al [4] showed the comparative performance analysis of EIGRP and OSPF routing protocols on real time applications such as video streaming. He evaluated these protocols on the basis of quantitative metrics such as convergence duration, packet delay variation, end-to end delay and throughput. Results show that EIGRP performs better over OSPF on real time video streaming applications. Sheela Ganesh Thorenoor [5] presented the implementation decisions to be made when the choice is between protocols that involve distance vector or link state or the combination of both and compared different parameters, finally it has been shown that EIGRP provides a better network convergence time, less bandwidth requirements and better CPU and memory utilization compared to OSPF. The paper compares the two protocols on the basis of E-mail upload response time and HTTP page response time [6] for different number of workstations.

\section{OPEN SHORTEST PATH FIRST (OSPF)}

OSPF is a link state routing protocol that uses a shortest path first algorithm to calculate the least cost path to all known destinations. OSPF follows Dijkstra algorithm for calculating the shortest path. Brief detail of this algorithm is given below [7]:

- When the router experiences any change in the routing information, it generates a link state advertisement that provides information to all the link states on the particular router.

- Link State Algorithms (LSAs) are exchanged by all the routers through flooding. Each router receives a link state update and stores in it a copy of link state database. This link state update propagates to all other routers.

- Once the database of each router is created, the routers start the search of shortest path by calculating shortest path tree to the destinations. The router uses Dijkstra algorithm for the purpose of finding the least cost path.

- Also the Dijkstra algorithm is recalculated to find the least cost path if there occurs any change in the OSPF network such as link cost, new network being added or deleted. 
Every router uses this algorithm at the root of the tree in order to find the shortest path on the basis of cost to reach the destinations [8].

\section{ENHANCED INTERIOR GATEWAY ROUTING PROTOCOL (EIGRP)}

Enhanced Interior Gateway Routing Protocol (EIGRP) is an improved version of the interior gateway routing protocol (IGRP) [9]. EIGRP is a CISCO proprietary protocol. It is a widely used IGRP and uses Diffusion Update Algorithm (DUAL) for the computation of the routes [10]. Moreover, EIGRP is considered as hybrid protocol because it has the properties of a link state protocol for creating neighbor relationships and of a distance vector routing protocol for advertisement of routes. The DUAL performs the following important tasks that comprise [11]:

- Maintenance of a topology table including all the entries found from the loop-free paths advertised by all routers.

- $\quad$ By using the distance information DUAL selects the best loop-free path i.e. successor path and second best loop free path i.e. feasible path from the topology table.

- Then DUAL saves the information into the routing table. The neighbor of the least cost route to the destination is called a successor

- Also DUAL inquires about the availability of any other best loop-free path using topology table in case the successor path is unreachable.

If there is no loop-free path in the topology table, the recalculation of the route is done and then the DUAL inquire its neighbors [12].

\section{OPNET MODELER}

Optimized Network Engineering Tool (OPNET) $[13,14,15,16]$ is commercial network simulation environment for network modeling. It is a powerful network simulator. It simulates the network graphically and its graphical editors mirror the structure of actual networks and network components. It provides a variety of toolboxes to design, simulate and analyze a network topology, routing protocols on the basis of various network parameters. Network with several hundreds of nodes can be managed. OPNET modeler version 14.5 is used for simulations.

\section{SIMULATION MODEL}

The model consists of $500 \mathrm{Km} \times 400 \mathrm{Km}$ enterprise network with three interconnected subnets: subnet_0, subnet_1, subnet_2. Each subnet consists of two switches, different number of routers (as stated in Table 1), three servers and three Workstations or LANs working on three different applications i.e. Database, E-mail and HTTP. Initially each subnet considered has individual workstations and the network was duplicated three times to have three scenarios. Then EIGRP was considered in the first scenario, OSPF in the second scenario and combination of both i.e. OSPF-EIGRP in the third scenario. The individual workstations are then replaced by LANs with 10 workstations, further the number of workstations was increased in the respective LANs to 25 and then to 50.The scenario is shown in figure 1 and the internal topologies of the subnets are shown in figures $2,3,4$.
Table 1: Number of routers in subnets.

\begin{tabular}{|c|c|}
\hline Subnet & Number of routers \\
\hline subnet_0 & 4 \\
\hline subnet_1 & 3 \\
\hline subnet_2 & 5 \\
\hline
\end{tabular}

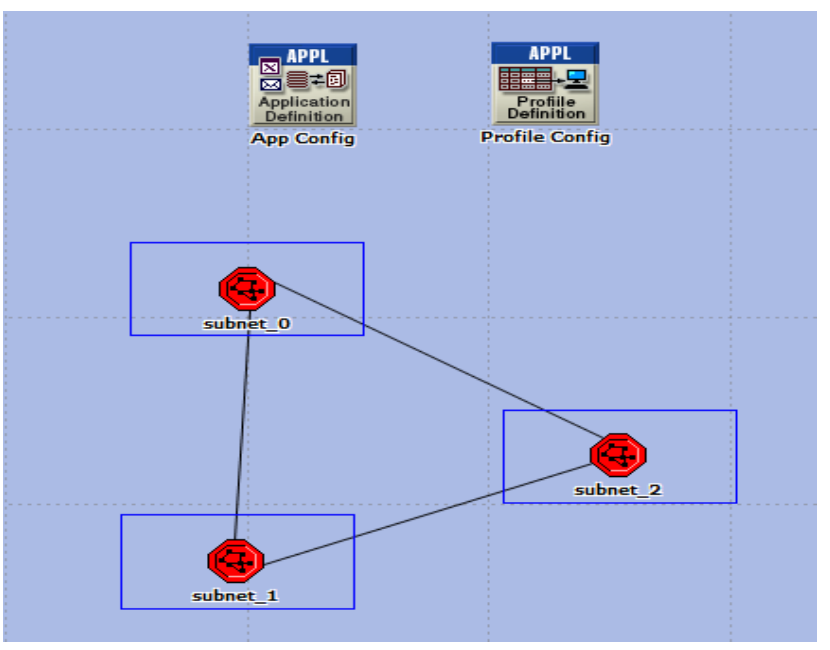

Fig 1: Network Scenario

The main characteristics of the scenario are depicted in Table 2.

Table 2: Main Characteristics of Scenario

\begin{tabular}{|c|c|}
\hline Parameters & Values \\
\hline Simulator & OPNET Modeler version 14.5 \\
\hline Protocols Studied & OSPF, EIGRP, OSPF-EIGRP \\
\hline Scenario Size & $500 \mathrm{Km} \times 400 \mathrm{Km}$ \\
\hline Number of Subnets & 3 \\
\hline Number of Workstations & $1,10,25$ and 50 \\
\hline Links & 100 BaseT, PPP_DS3 \\
\hline Applications & Database, E-mail, HTTP \\
\hline Simulation Duration & 1 hour \\
\hline Simulation Kernel & Optimized \\
\hline
\end{tabular}




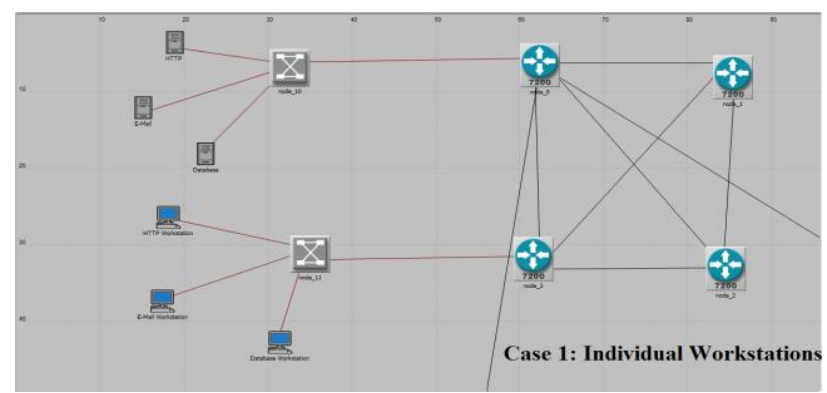

(a)

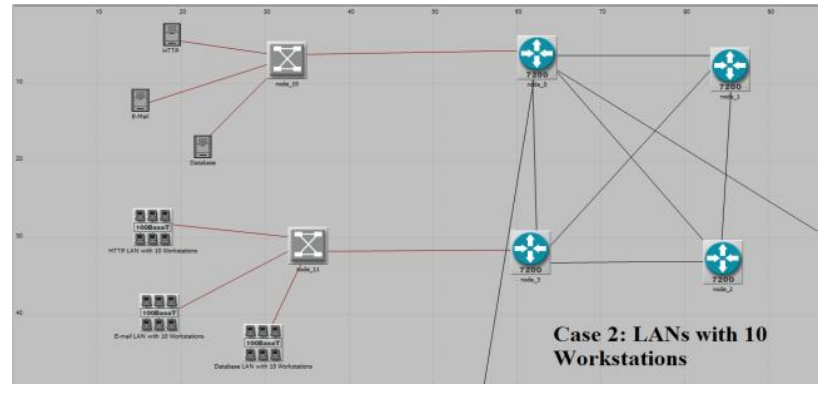

(b)

Fig 2 (a), (b): subnet_0 Topology

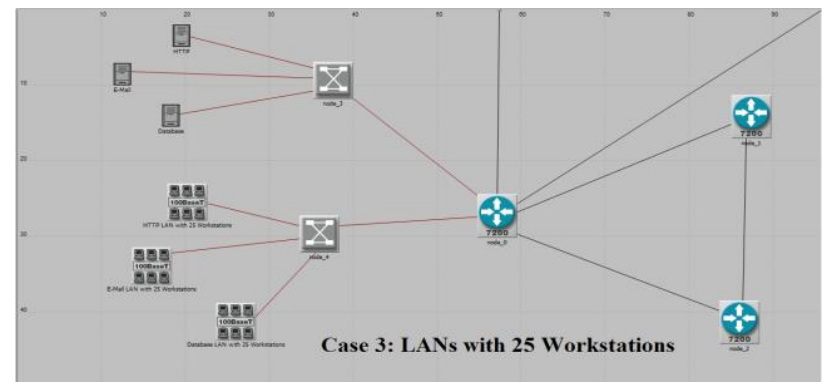

Fig 3: subnet_1 Topology

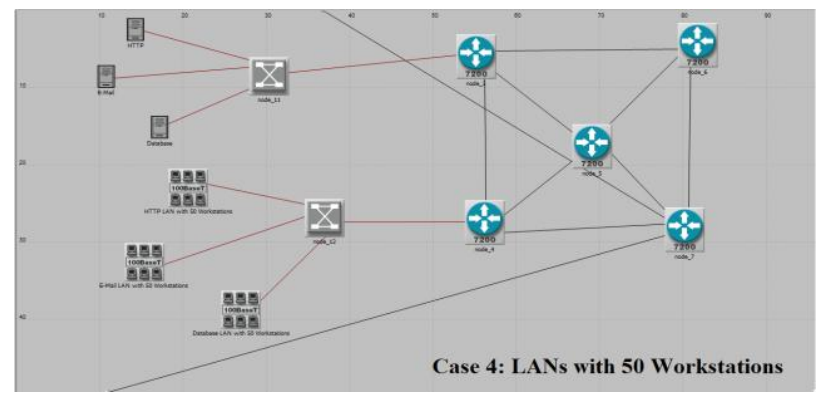

Figure 4: subnet_2 Topology

\section{SIMULATION RESULTS AND ANALYSIS}

The results of simulation are studied and analyzed to get the performance of two routing protocols i.e. OSPF, EIGRP and their combination for three different scenarios. The comparative analysis is based on the two parameters: e-mail upload response time, HTTP page response time. All the metric statistics are collected for different scenarios in all the cases as described in Table 3:

Table 3: Description of different cases.

\begin{tabular}{|c|c|}
\hline Case & $\begin{array}{c}\text { Number Of } \\
\text { Workstations }\end{array}$ \\
\hline Case 1 & 1 \\
\hline Case 2 & 10 \\
\hline Case 3 & 25 \\
\hline Case 4 & 50 \\
\hline
\end{tabular}

\subsection{E-Mail Upload Response Time}

E-mail application is heavily used by the users in the scenario, the E-mail access is done from the mail server in the network. Figures 5, 6, 7 and 8 shows E-mail upload response time in seconds for the cases 1, 2, 3 and 4 respectively. Observations shows that for OSPF and EIGRP the e-mail upload response time increases while shifting from case 1 to case 2 which then decreases in case 3 and again increases in case 4 . The fastest email upload response time of $0.01108 \mathrm{sec}$ and $0.011000 \mathrm{sec}$ is delivered by OSPF and EIGRP respectively in case 2 and the same slowest e-mail upload response time of $0.01005 \mathrm{sec}$ is given by both the protocols in case 1 . For the combination OSPF-EIGRP, the e-mail upload response time falls as the number of workstations extends up to 25 but possesses a slight increase when switching from 25 to 50 workstations which is almost negligible and the case of individual workstations delivers slowest e-mail upload response time with value 0.01125 $\mathrm{sec}$, being fastest with the value of $0.01069 \mathrm{sec}$ for 25 workstations.

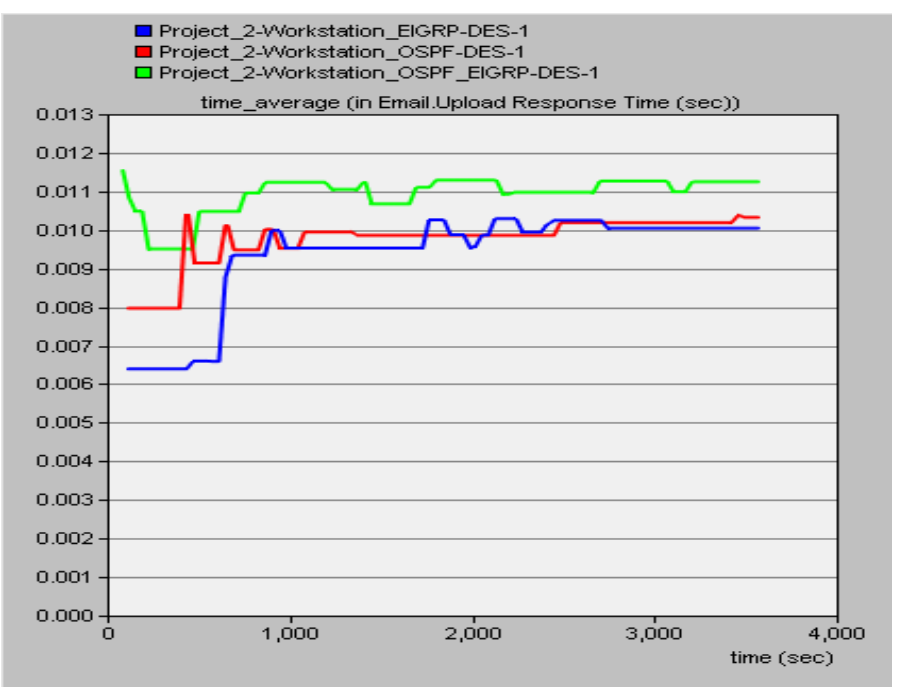

Fig 5: E-mail upload response time for case 1 


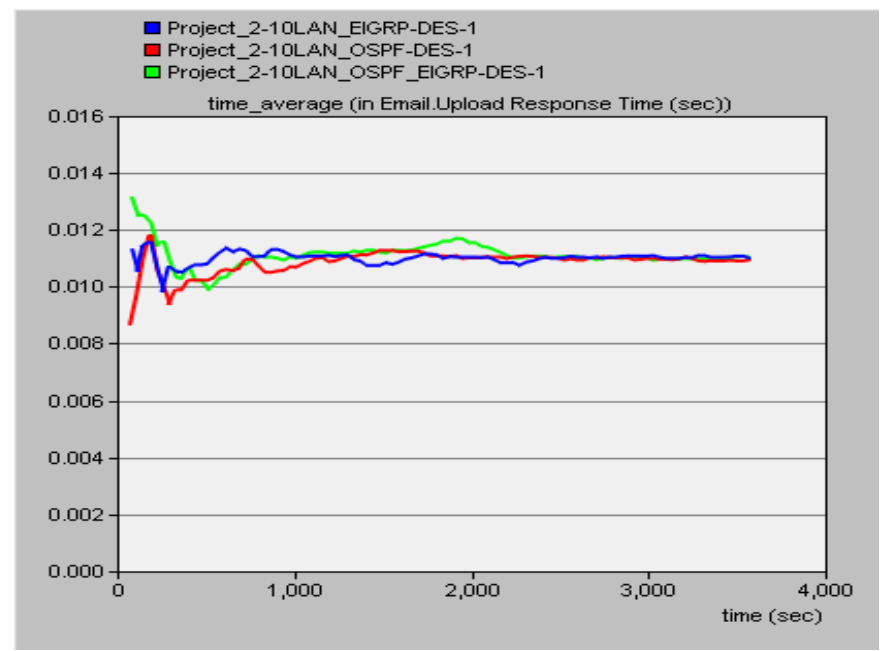

Fig 6: E-mail upload response time for case 2

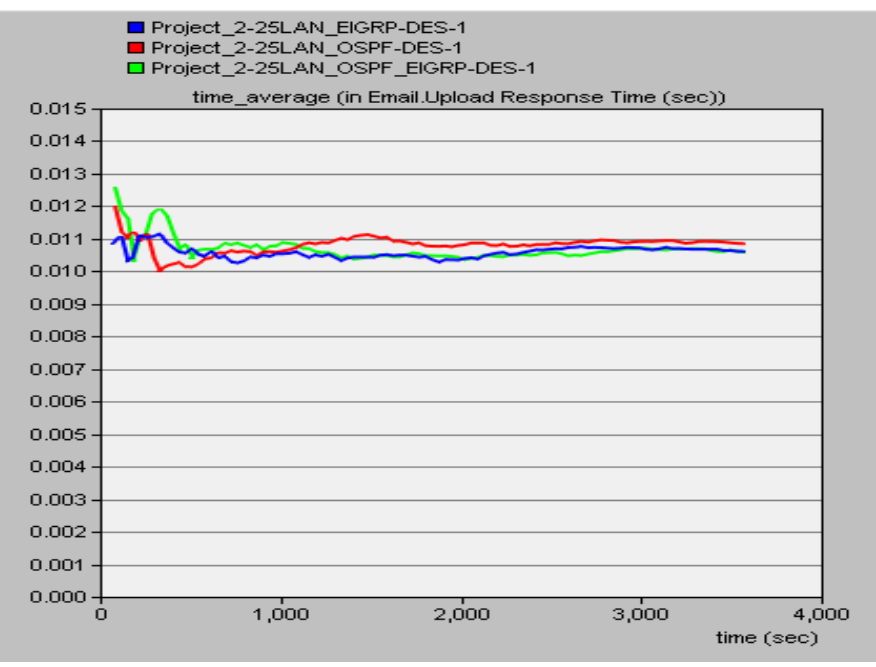

Fig 7: E-mail upload response time for case 3

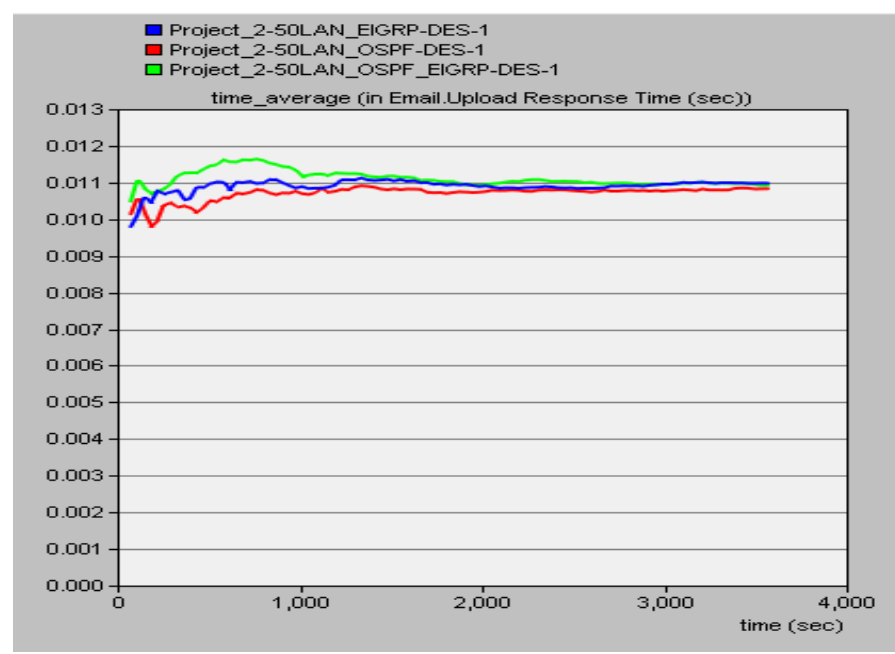

Fig 8: E-mail upload response time for case 4

\subsection{HTTP Page Response Time}

Heavy HTTP application is used by the users in the network and the application service is supported by the server. Figures 9, 10, 11 and 12 shows HTTP page response time in seconds for the cases 1, 2, 3 and 4 respectively. It was found that for OSPF and the combination OSPF-EIGRP the HTTP page response time increases when the individual workstations were replaced with 10 workstations but further decreases with increase in the number of workstations. OSPF and the combination OSPFEIGRP gives fastest HTTP page response time of $0.00871 \mathrm{sec}$ and $0.00808 \mathrm{sec}$ respectively for case 1 . EIGRP behaves in different way as the HTTP page response time decreases for extended number of workstations which is slowest for case 1 with value of $0.01029 \mathrm{sec}$

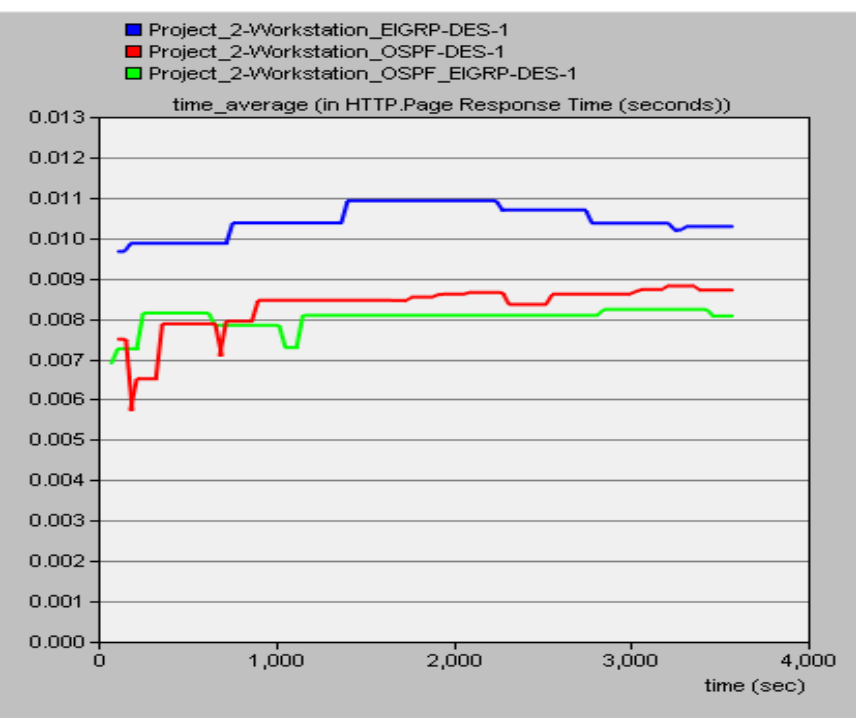

Fig 9: HTTP Page Response Time for case 1

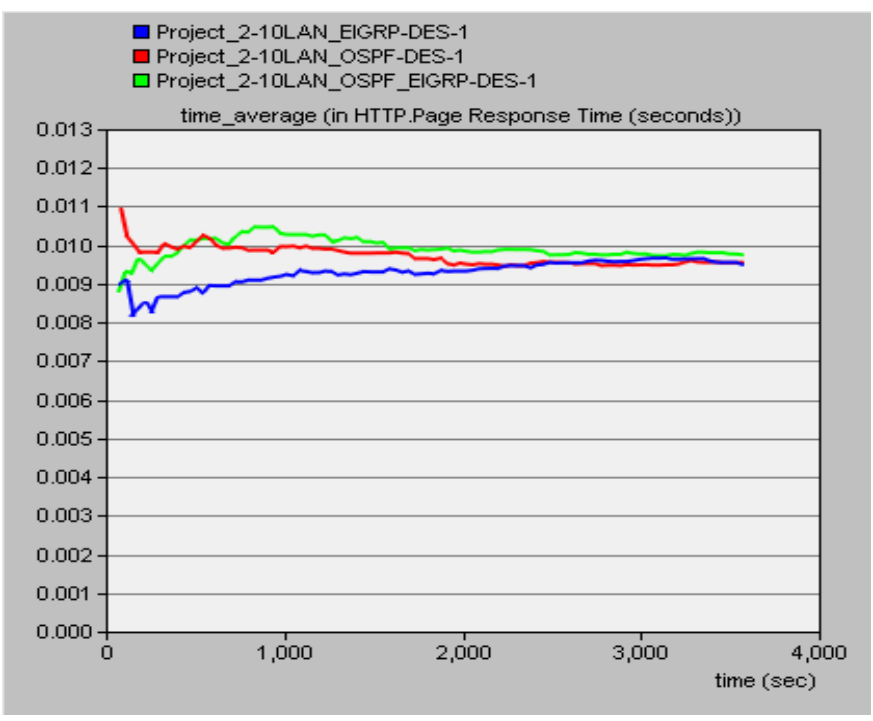

Fig 10: HTTP Page Response Time for case 2 


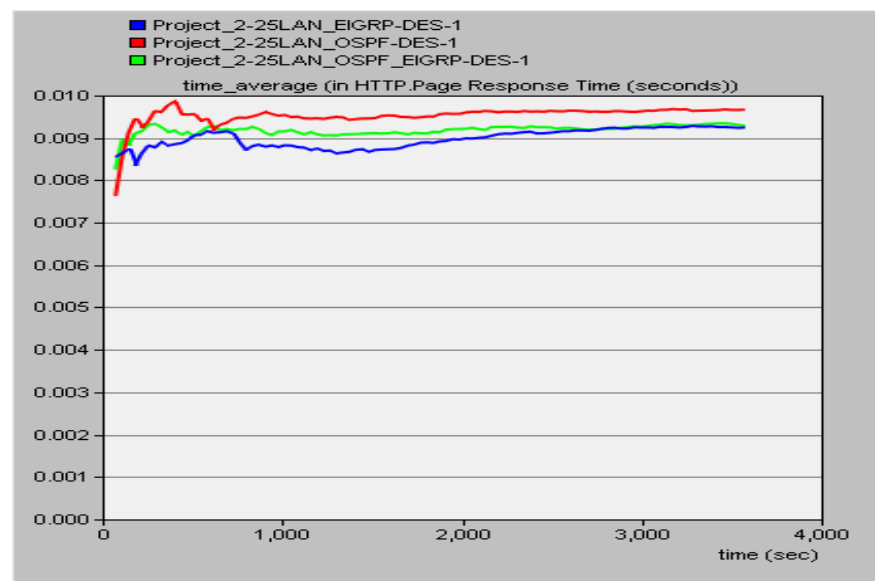

Fig 11: HTTP Page Response Time for case 3

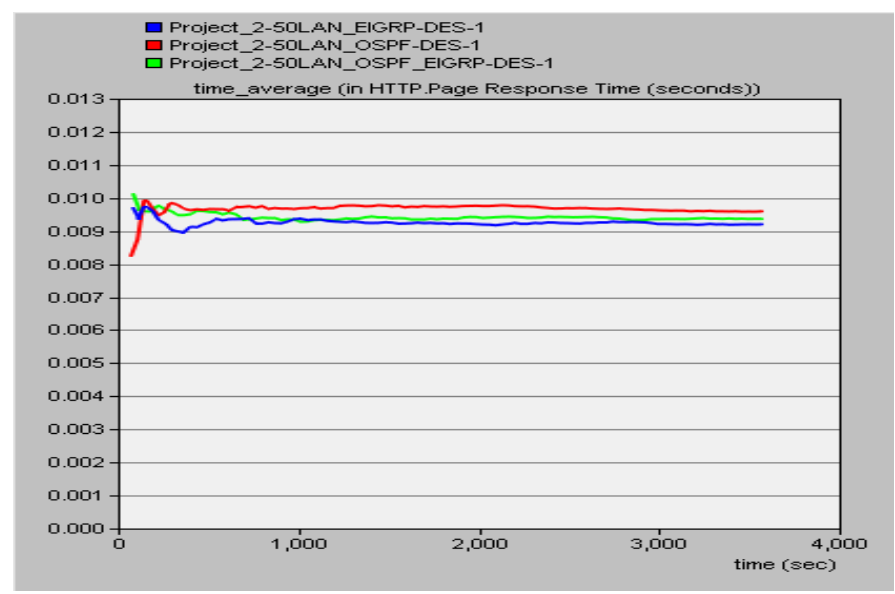

Fig 12: HTTP Page Response Time for case 4

\section{CONCLUSION}

Concluding the performance of the routing protocols it was observed that to have fastest e-mail upload response time EIGRP should be preferred for the workstations ranging from 1 to 25 but OSPF dominates in performance for 50 workstations however this difference is very small. Further to have fast HTTP page response time, again the preferred protocol is EIGRP except for the case of individual workstations giving slowest performance but as the number of workstations increases EIGRP performs well among all. Hence for the considered scenario overall best performance is delivered by EIGRP. It is considered that EIGRP is the preferred protocol for small networks but our network is a large scale network in which EIGRP performed well. Also EIGRP converges faster which means EIGRP is fast in response in comparison to OSPF, the point is again proved in the research.

\section{REFERENCES}

[1] Garcia-Luna-Aceves, J,J.; Zaumen, W.T “Area-based loopfree internet routing" Source: Proceedings IEEE INFOCOM 94. The Conference on Computer Communications. Networking for Global Communications (Cat. No. 94CH3401-7), 1000-8 vol.3,1994.
[2] Zhou Haijun1; Pan Jin1; Shen Pubing1 "Cost adaptive OSPF" Source: Proceedings Fifth International Conference on Computational Intelligence and Multimedia Applications. ICCIMA 2003, 55-60, 2003.

[3] Ittiphon krinpayorm and Suwat Pattaramalai "Link Recovery Comparison Between OSPF \& EIGRP” 2012 International Conference on Information and Computer Networks (ICICN 2012) IPCSIT vol. 27 (2012) (C) (2012) IACSIT Press, Singapore.

[4] Shafiul Hasan, Md. Nazmul Islam Khan, Mohammad Nazrul Islam , Md. Ahsan Ullah Ashique "Performance Evaluation of Dynamic Routing Protocols on Video Streaming Applications" Current Trends in Technology and Science, ISSN: 2279 - 0535. Volume: 2, Issue: 1.

[5] Sheela Ganesh Thorenoor "Dynamic Routing Protocol implementation decision between EIGRP, OSPF and RIP based on Technical Background Using OPNET Modeler" Second International Conference on Computer and Network Technology.

[6] RajanVohra, R.S.Sawhney, Manju Sharma"Analysis of Statistics HTTP and DATABASE for Wireless and Wireline Network with and without Load Balance",Proceedings of 2010 International Conference on Computer Communications and Networks (CCN-10) held in Orlando, Florida, USA ,pp. 123-129, July 2010.

[7] Cisco "OSPF Design Guide" http://www.cisco.com/en/US/tech/tk365/technologies_Whit e_paper09186a0080094e9e.shtml.

[8] Cisco "OSPF Design Guide" http://www.cisco.com/en/US/tech/tk365/technologies_Whit e_paper09186a0080094e9e.shtml.

[9] Rick Graziani and Allan Jonson, "Routing protocols and concepts: CCNA exploration companion guide" Pearson Education. London,2008.

[10] Al-Saud, K.A. Tahir, H.M.; El-Zoghabi, A.A.; Saleh, M.'Performance evaluation of secured versus non-secured EIGRP routing protocol" (Dept. of CS \& Eng., Qatar Univ., Doha, Qatar); Source: Proceedings of the 2008 International Conference on Security \& Management (SAM 2008), p 292-7, 2008.

[11] Nohl, A.R, Molnar, G "The convergence of the OSPF routing protocol" (Ericsson Res., Ericsson Hungary Ltd., Budapest, Hungary); . Source: Periodica Polytechnica Electrical Engineering, v 47, n 1-2, p 89-100, 2002.

[12] Ravi Malhotra, "IP Routing," 0-596-00275-0, January 2002.

[13] OPNET MODELER $\quad$ version 14.5 http://www.opnet.com/products/modeler.

[14] Wlan_lab_script_1_2 from http://www.comnets.unibremen.de/ mms/wlan_lab_script_ 1_2.pdf

[15] Walid Hneiti,"Performance Enhancement of Wireless Local Area Networks" Amman Arab University for Graduate Studies, Jordan. (2006).

[16] RajanVohra, R.S.Sawhney, Sunandika Mann “ Statistics Comparison in Wireless Network Environment for Balanced and Unbalanced Network" International Conference on Recent Advances and Future Trends in Information Technology (iRAFIT2012) Proceedings published in International Journal of Computer Applications ${ }^{\circledR}$ (IJCA). 